\title{
Ischiorectal Fossa
}

National Cancer Institute

\section{Source}

National Cancer Institute. Ischiorectal Fossa. NCI Thesaurus. Code C103455.

A tetrahedral region of adipose tissue located in the ischiorectal region with its base between the tuberosity of the ischium and the lower end of the rectum and its apex at the point where the obturator fascia and the Levator ani membrane divide. 